\title{
Zur Frage über die Einwirkung von Reduktionsmitteln auf Cholsäure. \\ Von \\ Alfr. Ekbom.
}

(Der Redaktion zugegangen am 29. Oktober 1906.)

Zahlreich sind die Versuche über die Einwirkung von Oxydationsmitteln auf Cholsäure, welche aus Rindergalle dargestellt ist; die Experimente haben jedoch das Problem von der Konstitution dieser Säure nicht lösen können. Ebenso sind auch verschiedene Reduktionsversuche mit Cholsäure ausgeführt worden; über die Konstitutionsfrage haben dieselben aber noch weniger Klarheit bringen können.

Es war, als ich die Untersuchungen über die chemische Natur der Cholsäure begann, meine Absicht, durch Wegnahme von Hydroxylgruppen mittels alkalischer Reduktionsmittel - bisher hatte man geglaubt, nur eine Hydroxylgruppe durch solche Mittel entfernen zu können (Vahlen und Mylius) ${ }^{1}$ ) - eine Säure darzustellen, die nur die Carboxylgruppe enthielt. Mit dieser Säure hätte ich wahrscheinlich einen Einblick in die konstitutive Zusammensetzung der Cholsäure erhalten können. Bald fand ich jedoch, daß die früheren Arbeiten, auf welche ich mich verlassen hatte, einer erneuerten Prüfung sehr bedürftig waren, und aus dem Grunde mußte ich eine Revision der Arbeiten über die Reduktion der Cholsäure ausführen.

Diejenigen Reduktionsexperimente mit Cholsäure, welche mit Hilfe von Zinkstaub von Destrem ${ }^{2}$ ) und Pregl, ${ }^{3}$ ) sowie

1) Diese Zeitschrift, Bd. XXIII, S. 99, und Ber. d. Deutsch. chem. Ges., Bd. XIX, 1, S. 374 .

2) Bulletin Soc. chim., Bd. XXXVII, S. 187, und C. R., Bd. LXXXVII, S. 880 .

3) Pflügers Archiv, Bd. LXXI, S. 303. 
mit Jodwasserstoffsäure von Pregl ${ }^{1}$ ) ausgeführt worden sind und welche nur amorphe, nicht reine Produkte gegeben hatten, kann ich beiseite lassen und ich werde in dem folgenden nur die anderen Reduktionsversuche kritisch prüfen, welche zur Isolierung von angeblich krystallisierenden Verbindungen geführt haben.

F. Mylius ${ }^{2}$ ) fand im Jahre 1886, daß, wenn Cholsäure mit Pankreasdrüsen in Fäulnis gebracht wird, Desoxycholsäure entsteht.

Elf Jahre später beschrieb Vahlen ${ }^{3}$ ) seine mit anorganischen Reduktionsmitteln ausgeführten Experimente an der Cholsäure wie folgt: "Ich entschloß mich um so lieber dazu, da man bisher bei dem Studium der Cholsäure hauptsächlich oxydierende Mittel auf sie hat einwirken lassen und wo man sie mit reduzierenden Mitteln angriff, dieselben sofort in so energischer Weise in Anwendung brachte, daß das ganze Molekül dabei in Stücke ging.» ${ }^{4}$ )

Vahlen behauptet auf Grund seiner Versuche, daß Desoxycholsäure entstehe, wenn Cholsäure, in Ammoniak gelöst, und Zinkstaub einige Tage bei Zimmertemperatur auf einander einwirken, und dieselbe Säure erhielt er ferner, als er Cholsäure, Zinkstaub und Eisessig in der Wärme auf einander einwirken ließ. Nach ihm soll aber Zinkstaub in ammoniakalischer Lösung sehr viel energischer als in essigsaurer einwirken, weil selbst mäßiges Erhitzen auf dem Wasserbad die Reaktion in jenem Falle bald so weit führt, daß in der vom überschüssigen Zinkpulver abfiltrierten Flüssigkeit mit Salzsäure keine harzigen Fällungen mehr zu bekommen sind. Das Verhalten der Cholsäure zu Zink und Essigsäure betreffend, schreibt Vahlen: « Nachdem ich mir Cholsäure durch Verseifen von Ochsengalle mit Natronlauge dargestellt hatte und dann durch Auflösen in Ammoniak und Fällen mit Chlorbaryum von Choleinsäure befreit hatte, löste ich sie in kochendem Eisessig und fügte Zinkstaub

1) Pflügers Archiv, Bd. LXXI, S. 303, und LXXII, S. 266.

3) Ber. d. Deutsch. chem. Ges., Bd. XIX, 1, S. 374.

s) Diese Zeitschrift, Bd. XXIII, S. 99.

4) Auf welche Untersuchung Vahlen mit diesen Worten hindeutet, habe ich nicht ermitteln können. 
hinzu. Darauf wurde sie auf kleiner Flamme mehrere Stunden am Rückflußkühler erwärmt. Erhitzt man zu stark, so wird sehr rasch die gesamte Cholsäure in einer Weise verändert, daß aus der verdünnten und neutralisierten Lösung auf Zusatz von Salzsäure überhaupt keine Fällung mehr entsteht. Andrerseits geht die Reaktion auf dem Wasserbade nur äußerst langsam vor sich. Nach mehreren Stunden filtriert man die eisessigsaure Lösung vom übriggebliebenen Zinkpulver $a b$ und verdünnt mit dem mehrfachen Volumen Wasser. Dabei scheidet sich die Cholsäure sofort in der bekannten harzigen Weise aus. Nun wurde sie nach wiederholtem Auswaschen in Ammoniak gelöst und mit Chlorbaryum gefällt. Es entsteht sofort ein Niederschlag oder eine reichliche, milchige Trübung, die sich nach einiger Zeit als amorpher Niederschlag absetzt. Dieser ist das Barytsalz einer durch Reduktion aus der Cholsäure entstandenen Säure.» Dieses Baryumsalz zerlegt Vahl en mit Sodalösung und im Filtrat von Baryumcarbonat stellt er durch Salzsäure die freie Säure dar; nach mehrmaligem Umkrystallisieren aus Eisessig schmolz die Säure bei 140-145 ${ }^{\circ}$. Aus diesem nicht scharfen Schmelzpunkt und aus nur einer Analyse schließt Vahlen, daß die so gewonnene Säure Desoxycholsäure ist.

Pregl ${ }^{1}$ ) hat sich sodann mit den alkalischen Reduktionsexperimenten Vahlens beschäftigt und dabei gefunden, daß keine wasserlöslichen Säuren entstehen, «wohl aber, daß bei längerem Erwärmen oder Kochen der ammoniakalischen Lösung von Cholsäure und Zinkstaub das sogar krystallisierte Zinksalz der organischen Säure ausfällt infolge Ammoniakverlustes der Lösung, denn durch einen neuerlichen Ammoniakzusatz vermag man das Ausgefallene wieder in Lösung zu bringen, worauf neuerliches Kochen wieder Fällung bewirkt». Wenn ich Pregl richtig verstanden habe, scheint er also der Ansicht zu sein, "daß das sogar krystallisierte Zinksalz der organischen Säure» das Zinksalz der Desoxycholsäure gewesen ist.

Es folgt also aus den Untersuchungen von Mylius, Vahlen

1) Sitzungsberichte der kaiserlichen Akademie der Wissenschaften (Wien), Bd. CXI, S. 1055. 
und Pregl, daß bei der Reduktion von Cholsäure immer Desoxycholsäure entsteht.

Hiermit gehe ich zu meinen eigenen Arbeiten über und gebe zuerst eine Übersicht der Resultate.

Das Fäulnisexperiment von Mylius habe ich wiederholt, habe jedoch bisher nicht das Entstehen von Desoxycholsäure konstatieren können. Chlorbaryumlösung gab freilich einen Niederschlag, aber dieser enthielt nur Fettsäuren. Es ist meine Absicht, in einer folgenden Arbeit ausfübrlich über dieses Experiment $\mathrm{zu}$ berichten.

Die Experimente Vahlens mit Ammoniak und Zinkstaub sind auch von mir nachgeprüft worden. Dabei habe ich gefunden, daß konzentriertes Ammoniak und Zinkstaub weder bei Zimmertemperatur während 6 Tagen noch bei $75^{\circ}$ während 7 Stunden auf Cholsäure einwirken. Die ursprüngliche Cholsäure wurde fast quantitativ unverändert wieder erhalten.

Weiter sind Versuche über die Einwirkung von Zink und Natriumhydratlösung ebenso wie von Schwefelwasserstoff auf Cholsäure ausgeführt worden. Die Experimente mit Zinkstaub und Natriumhydratlösung, welche bei verschiedenen Konzentrationen, sowohl bei Zimmertemperatur wie bei Siedetemperatur des Wassers während wechselnder Zeiten vorgenommen wurden, zeigten wie das Experiment mit Schwefelwasserstoff, daß diese Reduktionsmittel nicht auf Cholsäure einwirken; auch hier wurde die ursprüngliche Säure fast vollständig wieder gewonnen.

Endlich habe ich metallisches Natrium und 99\%igen siedenden Alkohol auf Cholsäure einwirken lassen. Auch hier konnte ich keine Reduktion beobachten; ich erhielt das ursprüngliche Material fast vollständig wieder.

Ich habe auch die Experimente Vahlens mit Zink, Eisessig und Cholsäure nachgemacht. Bei meinen Versuchen habe ich indessen der Kontrolle halber die Cholsäure nicht nur mit Eisessig und Zinkstaub, sondern auch mit Eisessig allein während wechselnder Zeit zum Sieden erhitzt, und ich machte dabei die unerwartete Erfahrung, daß das Resultat in beiden Fällen dasselbe blieb. Das Rohprodukt, welches nicht die Myliussche Cholsäurereaktion gab, wog immer mehr, als die in Arbeit ge- 
nommene Cholsäure und es stellte ein Gemenge von zwei Substanzen dar. Die eine, welche in verhältnismäßig kleiner Menge sich vorfand, gab eine in Wasser schwer lösliche Baryumverbindung; die Baryumverbindung der anderen, welche die Hauptmasse darstellte, war dagegen in Wasser leicht löslich. Da die Versuche mit oder ohne Zinkstaub stets unter sonst denselben Bedingungen ausgeführt wurden und dasselbe Produkt lieferten, konnte es offenbar nicht um eine Reduktion der Cholsäure zu Desoxycholsäure sich handeln. In Anbetracht dessen, daß das Rohprodukt immer mehr als das Ausgangsmaterial wog, hatte man entweder an eine molekulare Verbindung zwischen Cholsäure und Eisessig oder an die Entstehung von Acetylderivaten zu denken. Die weitere Untersuchung zeigte nun, daß das letztere tatsächlich der Fall war. Diejenige Substanz, welche eine praktisch unlösliche Baryumverbindung gab und aus diesem Grunde leicht mit Desoxycholsäure verwechselt werden konnte, erwies sich als ein Gemenge von Acetylderivaten. Die andere, welche eine leichtlösliche Baryumverbindung gab, war ein Monoacetylderivat. Diese Derivate sind dadurch entstanden, daß eine oder zwei der Hydroxylgruppen der Cholsäure gegen die Gruppe $\mathrm{CH}_{3} \mathrm{COO}$ ausgetauscht worden sind.

Ich habe also niemals eine Reduktion von Cholsäure und die Bildung von Desoxycholsäure beobachten können.

\section{Experimentelles.}

Die zu den Versuchen verwandte Cholsäure ist von meinem hochgeschätzten, leider zu früh verstorbenen Lehrer Prof. P. T. Cleve dargestellt worden. Sie zeigte nach Umkrystallisieren aus Alkohol den Schmelzpunkt 195-1960.1) Der Zinkstaub und

1) Bondi und Müller (Diese Zeitschrift, Bd. XLVII, S. 499) behaupten, daß der Schmelzpunkt der Cholsäure bei $198^{\circ}$ liegt. Sie hatten Cholsäure von diesem Schmelzpunkte dadurch erhalten, daß sie Cholsäure von dem Schmelzpunkte $194^{\circ} 4$ Stunden mit 10\% hydratlösung kochten und dann die Lösung mit Ghlorwasserstoffsäure versetzten. Ich habe diese Versuche nachzumachen versucht, aber ohne Erfolg. Beim Sieden am Rückflußkühler von $25 \mathrm{ccm} 9,7 \%$ iger Natriumhydratlösung und $1 \mathrm{~g}, 0,7 \mathrm{~g}, 0,5 \mathrm{~g}$ Cholsäure resp. schieden sich näm- 
der Eisessig waren von Kahlbaum bezogen; der Zinkstaub enthielt 88,78\% Zink (nach der Methode von Klemp, Z. f. anal. Chemie 29, bestimmt) und der Eisessig besaß den richtigen Siedepunkt. Sämtliche diese Präparate sind von meinem gegenwärtigen, hochverehrten Lehrer, Professor 0. Hammarsten, welcher mir auch einen Arbeitsplatz in seinem Laboratorium gegeben hat, $\mathrm{zu}$ meiner Verfügung gestellt worden. Ich benutze diese Gelegenheit, um ihm sowohl hierfür wie auch für das Interesse, mit welchem er meiner Arbeit gefolgt ist, und die Aufklärungen und Ratschläge, die er mir bei dem theoretischen und dem praktisch mühsamen Studium der interessanten, aber sehr verwickelten Chemie der Gallensäuren gegeben hat, meinen warmen und herzlichen Dank auszusprechen.

\section{Reduktionsversuche bei alkalischer Reaktion.}

$\mathrm{Zu}$ diesen Versuchen ist bei $120-130^{\circ}$ getrocknete Cholsäure benutzt worden und ich will schon hier die Aufmerksam. keit hierauf lenken, weil die zurückgewonnene Cholsäure immeı als krystallalkoholhaltig gewogen worden ist und weil es sons: unverständlich ist, daß die zurückgewonnene Cholsäure regelmäßig ein wenig mehr als die verwandte wog $-1 \mathrm{~g}$ wasser. oder alkoholfreie Cholsäure entspricht nämlich 1,11 g krystallalkoholhaltiger Säure. Die Rohprodukte - durch Ausfällen mi Chlorwasserstoffsäure (in allen Versuchen mit Ausnahme von den Experimente mit Schwefelwasserstoff), Auswaschen und Trocknel an der Luft erhalten - sind immer mit 99\% einem Kölbchen behandelt worden. Die Lösung wurde danı nach passendem Konzentrieren filtriert und die aus derselber krystallisierende Substanz nach dem Trocknen zwischen Filtrier-

lich reichlich Nadeln von Natriumcholat ab - beim Erkalten lösten sici wieder die Nadeln - die nach etwa einer halben Stunde ein so heftig6 Stoßen verursachten, daß die Versuche nicht fortgesetzt werden konnter. Ich erhitzte aus dem Grunde die Cholsäure mit Natronlauge - 0,5 g Chosäure und $10 \mathrm{ccm}$ der obigen Natriumhydratlösung - im Digestor de vorgeschriebene Zeit. Die so behandelte Cholsäure hatte fortwāhren den Schmelzpunkt 195-196 ${ }^{\circ}$. Ich muß jedoch betonen, daß ich niclt diese Experimente für entscheidend halte. 
papier gewogen (die Krystalle nehmen beim Trocknen über Schwefelsäure nicht an Gewicht ab). Filtrierpapier, Filtrum, Trichter und Krystallisationsgefäß wurden darauf mit 99\% Alkohol ausgelaugit bezw. gewaschen, diese alkoholische Lösung zur Mutterlauge der Krystalle gefügt, alles im oben erwähnten Kölbchen auf dem Wasserbade konzentriert, nach passender Konzentration filtriert und zur Krystallisation hingestellt. Das obige Verfahren wurde dann wiederholt, bis eine letzte Mutterlauge, die nur eine sehr kleine Menge Gallensäure enthielt, übrig blieb. Diese Mutterlauge wurde zum Trocknen abgedampft und der Rückstand mit Sodalösung versetzt. Aus der Lösung wurde (nach Filtrieren) die Gallensäure mit Chlorwasserstoffsäure ausgefällt, mit Wasser gewaschen und nach dem Trocknen an der Luft gewogen.

\section{A. Reduktionsversuche mit Cholsäure, Zink und} Ammoniak.

Experiment 1. $1 \mathrm{~g}$ Cholsäure wurde in $25 \mathrm{ccm}$ konzentriertem (0,91 spez. Gew.) Ammoniak gelöst und die Lösung mit $5 \mathrm{~g}$ Zinkstaub versetzt. Das Gemenge ließ ich unter zweimaligem täglichen Umschütteln in einem verschlossenen Kolben bei Zimmertemperatur $5^{1 / 2}$ Tage lang stehen. Während der Zeit der Einwirkung wurde eine sehr schwache Gasentwickelung beobachtet. Der Zinkrückstand wurde dann abfiltriert und das Filtrat, wie oben erwähnt ist, behandelt. Das Gewicht des Rohproduktes, welches die Reaktion von Mylius gab, betrug $0,97 \mathrm{~g}$. Dieses Produkt, in Alkohol gelöst, gab 0,92 g (zwei Fraktionen) tetraedische Krystalle vom Schmelzpunkte 195-196. Aus der Mutterlauge krystallisierten 0,05 g (2 Fr. $\left.{ }^{1}\right)$ ) tetraedische Krystalle mit einem etwas niedrigeren Schmelzpunkte aus. Endlich wog die aus der letzten Mutterlauge abgeschiedene, amorphe Gallensäure, welche die Reaktion von Mylius gab, 0,09 g. Ich habe also in diesem Experiment 0,97 g mit Alkohol krystallisierte Cholsäure und $0,09 \mathrm{~g}$ ausgefällte amorphe Cholsäure isoliert.

1) Ich bezeichne mit Fr. das Wort Fraktion. 
Experiment 2. $2 \mathrm{~g}$ Cholsäure, $50 \mathrm{ccm}$ konzentriertes Ammoniak $^{1}$ ) von 0,91 spezifischem Gewicht und $10 \mathrm{~g}$ Zinkstaulb wurden 7 Stunden lang bei $75^{\circ}$ am Rückflußkühler erhitzit. Nach dem Erkalten, Filtrieren und Auswaschen wurde das Filltrat wie im Experiment 1 verarbeitet. Das Rohprodukt worg 2,04 $\mathrm{g}$ und gab die Reaktion von Mylius. Beim Umkrystallisieren wurden zuerst $1,89 \mathrm{~g}$ (5 Fr.) tetraedische Krystalle vom Schmelzpunkt $195-196^{\circ}$ gewonnen, dann schieden sich $0,06 \mathrm{~g}$ (3 Fr.) tetraedische Krystalle vom Schmelzpunkt 191-19502) $\mathrm{ab}$ und weiter krystallisierten 0,04 g (2Fr.) tetraedische Krystalle, die bei etwa $190^{\circ}$ schmolzen, aus. Sowohl diese als die Quantität $0,08 \mathrm{~g}$, welche die letzte Mutterlauge gab, zeigten die Reaktion von Mylius. Folglich haben wir in diesem Experimente 1,99 g krystallisierte Cholsäure und 0,08 $\mathrm{g}$ ausgefälltes amorphes Produkt zurückgewonnen.

B. Reduktionsversuche mit Cholsäure, Zink und Natriumhydratlösung.

Experiment 1. $1 \mathrm{~g}$ Cholsäure wurde mit $25 \mathrm{ccm} 6 \%$ iger Natriumhydratlösung und $3 \mathrm{~g}$ Zinkstaub bei Zimmertemperatur in einem verschlossenen Kolben versetzt. Der Inhalt wurde zwei- bis viermal des Tages geschüttelt, wobei eine schwache Gasentwickelung bemerkt wurde. Das Experiment dauerte einen Monat. Es wurde dann wie in den Experimenten mit Ammoniak verfahren. Das Gewicht des Rohproduktes betrug 1,03 g. Dieses Produkt, welches die Reaktion von Mylius zeigte, gab zuerst 0,83 g (2 Fr.) tetraedrische Krystalle vom Schmelzpunkt 195-196 ${ }^{\circ}$, dann 0,15 g (4 Fr.) Krystalle vom Schmelzpunkt $190-195^{\circ}$. Diese wie auch die aus der letzten Mutterlauge gewonnene Menge, $0,12 \mathrm{~g}$, gaben die Jodcholsäurereaktion von Mylius. Also in diesem Experimente 0,98 $\mathrm{g}$ krystallisierte und $0,12 \mathrm{~g}$ amorphe Cholsäure.

Experiment 2. 1 g Cholsäure, 20 g 10\% ige Natriumhydratgesetzt.

1) Nach dem Verlaufe von כ̃ Stunden wurden noch $20 \mathrm{ccm} z u-$

2) Diese Zahlen geben den niedrigsten und den höchsten Schmelzpunkt, welcher in den verschiedenen Fraktionen beobachtet ist, an. 
Über die Einwirkung von Reduktionsmitteln auf Cholsäure. 105

lösung und $3 \mathrm{~g}$ Zinkstaub ließ ich aufeinander etwa ${ }^{1}$ ) zwei Wochen lang einwirken. Sonst wurde wie in den oben beschriebenen Experimenten verfahren. Das Rohprodukt wog $0,97 \mathrm{~g}$ und gab die Reaktion von Mylius. Beim Umkrystallisieren isolierte ich zuerst $0,77 \mathrm{~g}$ (1 Fr.) tetraedrische Krystalle vom Schmelzpunkt $195-196^{\circ}$ und dann 0,20 g (3 Fr.) tetraedrische Krystalle vom Schmelzpunkt $192-195^{\circ}$. Endlich wog die Gallensäure, welche amorph ausgefällt wurde, $0,07 \mathrm{~g}$, und diese gab ebenfalls die Myliussche Reaktion. Folglich in diesem Experimente 0,97 g krystallisierte und 0,07 g amorphe Cholsäure.

Experiment 3. $100 \mathrm{~g}$ einer Natriumcholatlösung, welche $2 \%$ Cholsäure und $0,4 \%$ Natriumhydrat enthielt, wurden mit 20) $\mathrm{g} \mathrm{10 \%}$ iger Natriumhydratlösung und $3 \mathrm{~g}$ Zinkstaub versetzt und das Gemenge am Rückflußkühler bei ungefähr $100^{\circ}$ (kochendes Wasser) 8 Stunden 45 Minuten lang erhitzt. Nach dem Filtrieren (nach 36 Stunden) wurde das Filtrat wie oben behandelt und das Gewicht des Rohproduktes, welches die Reaktion von Mylius zeigte, betrug $1,95 \mathrm{~g}$. Beim Umkrystallisieren schieden sich $1,64 \mathrm{~g}$ (2 Fr.) tetraedrische Krystalle vom Schmelzpunkt $195-196^{\circ}$ aus, deren Mutterlauge 0,38 g (7 Fr.) tetraedrische Krystalle vom Schmelzpunkt 189-1940 lieferte. Die zuletzt ausgefällte Gallensäure wog $0,09 \mathrm{~g}$ und gab die Reaktion von Mylius. Hieraus sehen wir, daß 2,02 g krystallisierte und 0,09 $\mathrm{g}$ amorphe Cholsäure wieder erhalten sind.

Experiment 4. $2 \mathrm{~g}$ Cholsäure wurden in $40 \mathrm{ccm} 10 \%$ iger Natriumhydratlösung gelöst, $7 \mathrm{~g}$ Zinkstaub zugefügt und wie im Experimente 3 während 8 Stunden erhitzt. Das Rohprodukt wog $2,05 \mathrm{~g}$, gab die Reaktion von Mylius, lieferte beim Umkrystallisieren zuerst $1,64 \mathrm{~g}(1 \mathrm{Fr}$.) tetraedrische Krystalle vom Schmelzpunkt 195-196 ${ }^{\circ}$, dann 0,45 g (4 Fr.) tetraedrische Krystalle, welche bei $190-195^{\circ}$ schmolzen, und endlich $0,08 \mathrm{~g}$ ausgefällte Gallensäure mit der Reaktion von Mylius. Folglich in diesem Experiment 2,09 g krystallisierte und 0,08 g amorphe Cholsäure.

$0,309 \mathrm{~g}$ (über Schwefelsäure getrocknet) von den in den Experimenten 1-4 aus den letzten Mutterlaugen ausgefällten

1) Die Zeit für den Anfang des Experimentes vergaß ich leider aufzuzeichnen.

Hoppe-Seyler's Zeitschrift f. physiol. Chemie. L. 
amorphen Gallensäuren wurden mit Ammoniak versetzt, die Lösung auf $30 \mathrm{ccm}$ verdünnt und dann mit $20 \mathrm{ccm} 20 \%$ iger Chlorbaryumlösung behandelt. Es entstand nicht sofort, sondern erst nach einiger Zeit ein unbedeutender Niederschlag, welcher nach 18 Stunden mit $20 \mathrm{ccm}$ von der erwähnten Chlorbaryunlösung gewaschen wurde. Dieser Niederschlag wurde nicht weiter verarbeitet. Dessen Filtrat lieferte dagegen mit Chlorwasserstoffsäure eine ziemlich große Fällung, welche nach dem Trocknen über Schwefelsäure $0,233 \mathrm{~g}$ wog. Das Filtrat von diesem Niederschlag wurde dann mit Sodalösung bis zur alkalischen Reaktion versetzt, nach der Filtration beinahe zur Trockene abgedampft und der Rückstand mit 95\% igem Alkohol behandelt. Nach dem Abfiltrieren vom Chlornatrium und vom Natriumcarbonat wurde das Filtrat zur Trockene abgedampft, der Rückstand in Wasser gelöst und die Lösung mit Chlorwasserstoffsäure versetzt. Die auf diese Weise erhaltene Gallensäure wog $0,061 \mathrm{~g}$ (über Schwefelsäure getrocknet). Die 0,294 $\mathrm{g}$ gaben die Reaktion von Mylius und 0,164 $\mathrm{g}$ tetraedrische Krystalle. Die Mutterlauge konnte wegen des Schlusses des Laboratoriums leider nicht verarbeitet werden.

C. Reduktionsversuche mit Cholsäure, in Ammoniak gelöst, und Schwefelwasserstoff.

$1 \mathrm{~g}$ Cholsäure wurde in $10 \mathrm{ccm}$ konzentriertem Ammoniak vom spezifischen Gewicht 0,91 gelöst und in die Lösung Schwefelwasserstoff $1^{1 / 2}$ Stunden lang eingeleitet. Die Temperatur war im Anfang des Experimentes $11^{\circ}$, am Ende $7^{\circ}$. Nach etwa 16 Stunden wurde die Lösung auf dem Wasserbade zur Trockne abgedampft, der aus freier Cholsäure ${ }^{1}$ ) und Schwefel bestehende Rückstand mit Ammoniak behandelt und der Schwefel abfiltriert. Da ein wenig Schwefel durch das Filtrum ging, wurde die Lósung aufs neue zur Trockene abgedampft; hierbei schieden sich weiße Krystalle ab. Nachdem der Rückstand darauf in Ammoniak gelöst worden war, filtrierte ich die Lösung und konzentrierte stark, wobei ein reichlicher Niederschlag entstand;

1): Das Ammoniumcholat zerfällt nämlich in Ammoniak und Ghelsäure. Weiteres hierüber Seite 108. 
dieser wurde abfiltriert, an der Luft getrocknet und dann aus Alkohol umkrystallisiert. Tetraedrische Krystalle, 0,83 g (2 Fr.), mit dem Schmelzpunkt des Ausgangsmaterials wurden zuerst isoliert, dann 0,12 g (4 Fr.) vom Schmelzpunkt 189-194 ${ }^{\circ}$. Die letzte Mutterlauge lieferte endlich $0,12 \mathrm{~g}$ Gallensäure mit der Reaktion von Mylius. Es wurden also $0,95 \mathrm{~g}$ krystallisierte and $0,12 \mathrm{~g}$ amorphe Cholsäure wieder gewonnen.

$1,17 \mathrm{~g}$ der in den oben erwähnten Versuchen gewonnenen, tetraedrischen Krystalle von niedrigerem Schmelzpunkt als $195^{\circ}$ wurden aus Alkohol umkrystallisiert und es schieden sich zuerst $0,89 \mathrm{~g}$ (2 Fr.) vom Schmelzpunkt $195-196^{\circ}$ aus, dann $0,10 \mathrm{~g}$ vom Schmelzpunkt $193-194^{\circ}$ und weiter 0,13 g (2 Fr.) tetraedrische Krystalle vom Schmelzpunkt 191-1940. Endlich gab die letzte Mutterlauge $0,05 \mathrm{~g}$ Gallensäure mit der Reaktion von Mylius.

D. Reduktionsversuch mit Cholsäure, in 99\% igen Alkohol gelöst, und Natrium.

$2 \mathrm{~g}$ bei $100^{\circ}$ getrocknete Cholsäure wurden in $20 \mathrm{~g} 99^{\circ} \%$ igem Alkohol gelöst und die Lösung zum Sieden ảm Rü̈ckflußkühler erhitzt. Während der Erhitzung ( $3^{3 / 4}$ Stunden) wurden von Zeit zu Zeit Natriumscheiben, insgesamt $4 \mathrm{~g}$, eingeführt und na'ch ungefähr 2 Stunden, da der Kolbeninhalt dickflüssig wurde, wurden noch $4 \mathrm{~g}$ des erwähnten Alkohols zugesetzt. Nach $\mathrm{Zu}$ satz von Wasser wurde alles auf dem Wasserbade verdunstet, bis der meiste Alkohol verjagt worden war, worauf das $A^{\prime} b$ dampfen in einer Schale fortgesetzt wurde. Wenn kein Geruch nach Alkohol mehr bemerkbar war, wurde die Lösung filtriert und das Filtrat wie oben verarbeitet. Das Rohprodukt, mit einem Stich ins gelbliche; wog 2,09 g und gab die Reaktion von Mylius. Nach dem Umkrystallisieren gab dieses Produkt zuerst $1,8 \mathrm{~g}$ (2 Fr.) tetraedrische Krystalle vom Schmelzpunkt $195-196^{\circ}$, dann $0,13 \mathrm{~g}$ tetraedrische Krystalle vom Schmelzpuinkt $194-195^{\circ}$ und weiter $0,15 \mathrm{~g}$ (3 Fr.) Krystalle von Schmelzpunkt $190-193^{\circ}$. Die ausgefällte amorphe Gallensäure (aus der letzten Mutterlauge) wog 0,11 g. und zeigte die Reaktion vorn Myliưs. Folglieh in diesem Experimente $2,08 \mathrm{~g}$ krystallisierte und $0,11 \mathrm{~g}$ ausgefällte, amorphe Cholsäurèe. 
Bemerkungen zu den Experimenten bei alkalischer Reaktion.

In allen meinen Versuchen mit Cholsäure und Reduktionsmitteln in alkalischer Lösung habe ich also die angewandte Cholsäure fast ganz quantitativ zurückgewinnen können und die Bildung von Desoxycholsäure habe ich nie beobachtet. Die Angabe Vahlens, daß beim Behandeln der Cholsäure mit Zinkstaub in ammoniakalischer Lösung selbst beim mäßigen Erhitzen auf dem Wasserbade die Reaktion soweit geführt wird, daß mit Salzsäure keine harzigen Fällungen mehr zu bekommen sind, muß ich unter Hinweis auf die oben unter A beschriebenen Versuche als entschieden unrichtig bezeichnen. Die Unhaltbarkeit dieser Behauptung Vahlens ist übrigens schon früher von Pregl ${ }^{1}$ ) hervorgehoben worden. Dagegen kann ich diesem Autor nicht beistimmen, wenn seine Behauptung, daß das Zinksalz der organischen Säure infolge Ammoniakverlustes der Lösung sogar krystallinisch sich ausscheidet, derart $\mathrm{zu}$ deuten ist, daß er mit der organischen Säure Desoxycholsäure oder eine andere aus Cholsäure entstandene Säure versteht. Ich behaupte vielmehr, daß die Säure Cholsäure gewesen ist, jedoch kann ich nicht die Möglichkeit in Abrede stellen, daß Pregl ein Zinksalz dieser Säure gewonnen hat. Ich bin aber der Meinung, daß dieses nicht wahrscheinlich ist, sondern daß es sich um krystallisierte Cholsäure gehandelt hat, denn beim Erhitzen des Ammoniumcholats zerfällt dasselbe durch Hydrolyse in Ammoniak und Cholsäure, welche letztere in dem Maße, wie das Ammoniak entweicht, sich nach dem folgenden Schema ausscheidet: ${ }^{2}$ )

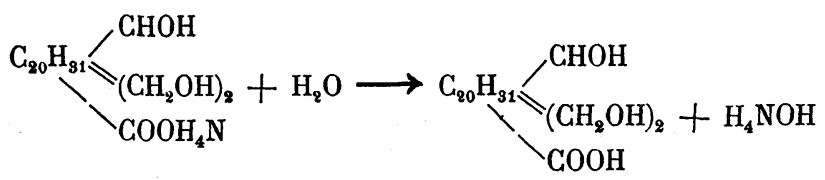

Aus meinen Untersuchungen folgt ferner, daß bei Reduktion (wie bei Oxydation) der Gallensäurekern im hohen Grade stabil

1) Sitzungsberichte (1. c.), S. 1055.

2) Siehe das Experiment mit Cholsäure in ammoniakalischer Lösung und Schwefelwasserstoff. 
ist; derselbe zerfällt nicht leicht in Bruchstücke. Dieses wird auch durch meine folgenden Experimente bestätigt.

In einem Experimente erhitzte ich $1 \mathrm{~g}$ Cholsäure mit $25 \mathrm{ccm} 10 \%$ iger Natriumhydratlösung im eisernen Bombenrohr 1 Stunde bei $125-168^{\circ}$ (die niedrigste Temperatur während des Versuches war $128^{\circ}$, die höchste $168^{\circ}$; es wurden nach dem Filtrieren, Zusatz von Chlorwasserstoffsäure und Auswaschen 1,04 g lufttrockenes Rohprodukt gewonnen, ein Produkt, welches die Reaktion von Mylius gab. Aus ihm erhielt ich mit Alkohol zuerst $0,78 \mathrm{~g}$ (1 Fr.) tetraedische Krystalle mit einem Schmelzpunkt zwischen $197-198^{\circ}$ ) und dann 0,15 g (3 Fr.) Krystalle vom Schmelzpunkte 194-196. ${ }^{2}$ ) (Die Mutterlauge ging verloren.) In einem zweiten Experimente wurde bei $182-196^{\circ} 1 \mathrm{~g}$

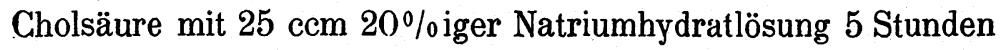
lang erhitzt; hier erhielt ich 0,97 g Rohprodukte mit Mylius' Reaktion. Aus dieser Quantität wurden zuerst 0,80 g (2 Fr.) tetraedrische Krystalle vom Schmelzpunkt $195-196^{\circ}$ isoliert, dann 0,19 g (4 Fr.) Krystalle vom Schmelzpunkt 191-194. Die aus der letzten Mutterlauge mit Salzsäure ausgefällte amorphe Gallensäure wog $0,05 \mathrm{~g}$ und gab die Reaktion von Mylius. In einem dritten Experimente wurde aus $1 \mathrm{~g}$ Cholsäure, mit $25 \mathrm{ccm}$ $10 \%$ iger Natriumhydratlösung während 3Stunden 15 Minuten bei $.200-211^{\circ}$ erhitzt, $1 \mathrm{~g}$ Rohprodukt mit der Reaktion von Mylius gewonnen. Erst bei $259-266^{\circ}$ schien es, als ob eine Einwirkung auf die Cholsäure stattgefunden hätte. Da bei dieser Temperatur $1 \mathrm{~g}$ Cholsäure und $25 \mathrm{ccm} 20 \%$ iger Natriumhydratlösung 6 Stunden 50 Minuten lang erhitzt wurden, erhielt ich nämlich als Rohprodukt $0,88 \mathrm{~g}$, welche nicht die Reaktion von Mylius zeigten. Indessen gelang es mir, aus dieser Quantität $0,3 \mathrm{~g}$ in Tetraedern krystallisierte Cholsäure $\mathrm{zu}$ isolieren.

Nachdem ich so die Reduktionsversuche bei alkalischer Reaktion besprochen habe, sollte ich demnächst zu den Reduktionsversuchen mit Zink in saurer Lösung übergehen. Da aber bei diesen Versuchen die Möglichkeit einer Bildung von

1) Ich habe in meinen Versuchsprotokollen diese Zahlen geschrieben; ich vergaß leider über die Fraktion I eine nähere Untersuchung zu machen.

$\left.{ }^{2}\right)$ Siehe Seite 104, die Note ${ }^{2}$ ). 
Acetylderivaten nicht ausgeschlossen war, hielt ich es für notwendig, Versuche mit Cholsäure und Eisessig allein auszuführen. Ich will also zuerst über diese Versuche berichten.

\section{II. Über die Einwirkung von Eisessig auf Cholsäure.}

Auch $\mathrm{zu}$ diesen Versuchen wurde bei $120^{\circ}$ getrocknete Cholsäure verwendet. Sie wurde mit Eisessig in einem Kolben mit Rückflußkühler auf einer Asbestplatte verschieden lange Zeit in den verschiedenen Versuchen im Sieden erhalten. Darauf wurde die Lösung in eine größere Quantität Wasser eingegossen und die entstandene, voluminöse Fällung mit Wasser fein zerrieben, genau ausgewaschen und an der Luft zum konstanten Gewicht getrocknet. Der so behandelte Niederschlag wird als Rohprodukt 1 bezeichnet. Das von ihm getrennte Filtrat enthielt regelmäßig etwas Substanz, welche, wie besondere Versuche zeigten, ebenfalls nicht die Reaktion von Mylius gab. Diese Substanz, als Rohprodukt 2 bezeichnet, wurde in zweí Versuchen (3 und 4) als solche, in den zwei anderen (1 und 2) dagegen erst nach dem Behandeln mit überschüssiger Sodalösung in der Wärme und Ausfällung mit Chlorwasserstoffsäure aufgesammelt. Die verschiedenen Rohprodukte 2 wurden immer nach Auswaschen an der Luft zum konstanten Gewicht getrocknet.

Das Rohprodukt 1 wurde in Ammoniak gelöst und diese Lösung mit gesättigter Chlorbaryumlösung versetzt. Nach einer bestimmten Zeit wurde der Niederschlag aufs Filtrum genommen und mit gesättigter Chlorbaryumlösung gewaschen. Der Niederschlag und das von ihm getrennte Filtrat wurden gesondert mit Salzsäure behandelt; die in Freiheit gesetzten Gallensäuren mit Wasser bis zum Verschwinden der Baryumreaktion gewaschen und an der Luft bis zur Gewichtskonstanz getrocknet. Das Produkt aus der Baryumfällung bezeichne ich als $\mathrm{A}$ und das aus dem Filtrate als $B^{1}$ ) - diese Produkte gaben, wie das Rohprodukt 1, nie die Reaktion von Mylius.

Experiment 1. $1 \mathrm{~g}$ Cholsäure wurde 4 Stunden 15 Minuten lang mit $10 \mathrm{~g}$ Eisessig erhitzt. Das Gewicht des Rohproduktes 1

1) Über das Verhältnis zwischen den Gewichten des Produktes B in lufttrockenem und exsikkatortrockenem Zustande, siehe Seite 122, die erste Note. 
betrug 1,04 g. Der durch Chlorbaryumlösung erzeugte Niederschlag war gelb gefärbt und teigig, wurde aber durch Reiben ganz fest. Die Gewichte der Produkte A und B betrugen $0,34 \mathrm{~g}$ und $0,5 \mathrm{~g}$ respektiv.

Das Filtrat von dem Rohprodukte 1 wurde abgedampft, bis die größte Menge Eisessig verjagt war, und darauf, wie oben (S. 110) beschrieben, mit Sodalösung behandelt. Das Rohprodukt 2 wog $0,10 \mathrm{~g}$ und zeigte die Reaktion von Mylius.

Experiment 2. $5 \mathrm{~g}$ Cholsäure wurden mit $50 \mathrm{ccm}$ Eisessig während 4 Stunden 15 Minuten erhitzt (eigentliches Sieden konnte ich in diesem Experimente nicht beobachten). Als die Lösung mit viel Wasser versetzt wurde, schieden sich als Rohprodukte 1 sowohl eine amorphe Fällung als eine halbfeste Masse aus, welche nach einigen Tagen (die halbfeste Masse wurde allmählich fest) wie oben erwähnt (S. 110) zusammen behandelt wurden. Das Rohprodukt 1 wog 5,62 g. In der ammoniakalischen Lösung des Produktes 1 entstand mit gesättigter Chlorbaryumlösung sogleich kein Niederschlag; am folgenden Tage beobachtete ich aber eine unbedeutende Fällung, die nach Verlauf von 48 Stunden abfiltriert wurde. Diese Fällung enthielt viel Baryumcarbonat und gab von dem Produkte A nur 0,04 g. Die Menge des Produktes B war dagegen 5,32 g.

Das Filtrat von dem Rohprodukte 1, wie das entsprechende Filtrat im Versuche 1 behandelt, lieferte 0,18 Gallensäure (das Rohprodukt 2), welche die Reaktion von Mylius gab.

Aus diesen Versuchen sehen wir also, daß die Rohprodukte 1, welche die Reaktion von Mylius nicht gaben, bezw. 1,04 g und $\overline{5}, 62 \mathrm{~g}$, also mehr als die ursprünglichen Cholsäuremengen, bezw. $1 \mathrm{~g}$ und $5 \mathrm{~g}$, wogen und daß die Rohprodukte 2 erst nach der Verseifung die Reaktion von Mylius gaben. Hieraus kann man also mit Wahrscheinlichkeit schließen, daß entweder eine molekulare Verbindung zwischen Cholsäure und Essigsäure oder ein Acetylderivat entstanden ist.

Die erste Annahme kann jedoch schon der Behandlung des Materials zufolge mit Wahrscheinlichkeit ausgeschlossen werden. Folgendes Experiment zeigt auch das Unzulässige einer solchen Annahme. 
Titrierungsexperiment. ${ }^{1}$ ) Von dem Produkte B (Versuch 2) wurden $0,4150 \mathrm{~g}$, über Schwefelsäure zum konstanten Gewicht getrocknet, in Alkohol von 99\% gelöst, und die Lösung mit einer Natriumhydratlösung (Phenolphtalein als lndikator)

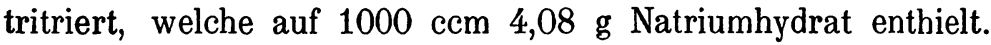
Es wurden zur Neutralisation $9,0 \mathrm{ccm}$ derselben verbraucht.

Dieses Experiment zeigt, daß hier keine molekulare Verbindung vorliegt, denn eine solche von der Zusammensetzung $\mathrm{C}_{24} \mathrm{H}_{40} \mathrm{O}_{5}+\mathrm{C}_{2} \mathrm{H}_{4} \mathrm{O}_{2}$ z. B. verlangt (auf $0,4150 \mathrm{~g}$ berechnet) $17,39 \mathrm{ccm}$ der erwähnten Natronlauge. Dagegen wird das Vorhandensein eines Monoacetylderivates sehr wahrscheinlich, indem nämlich ein solches 9,04 ccm der obigen Natriumhydratlösung verlangt.

Folglich haben wir bei der Erhitzung von Cholsäure mit Eisessig ziemlich sicher Acetylderivat erhalten.

Die Entstehung von Acetylderivaten wird jedoch erst durch das folgende Experiment zur vollen Evidenz bewiesen.

Verseifungsexperiment. Von dem Produkte B (Versuch 2) wurden $0,4600 \mathrm{~g}$ (über Schwefelsäure zum konstanten Gewicht getrocknet) mit $10 \mathrm{ccm}$ einer Baryumhydratlösung, welche

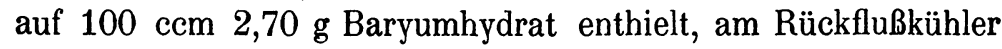
$3 / 4$ Stunde lang gekocht. Nach Abkühlung wurde der Inhalt

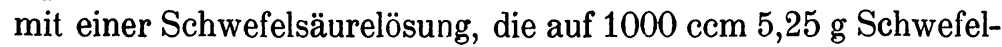
säure enthielt, titriert; und es wurden dabei $9,8 \mathrm{~cm}$ zur Neutralisation verbraucht. Darauf wurden $19,6 \mathrm{ccm}$ von der Schwefelsäurelösung zugesetzt, um sämtliches Baryum als Baryumsulfat zu erhalten, und nach 2\& Stunden die Fällungen von Baryumsulfat und Gallensäure abfiltriert und ausgewaschen. Die Niederschläge wurden dann mit Sodalösung in der Wärme (um Baryumsulfat von der Gallensäure zu trennen) behandet; nach Filtrieren wurde Chlorwasserstoffsäure zugesetzt. Das so gewonnene Verseifungsprodukt wog nach dem Auswaschen und Trocknen an der Luft 0,33 g; diese Quantität gab die Reaktion von Mylius.

Das Filtrat von dem Baryumsulfate und dem nicht gereinigten Verseifungsprodukte wurde der fraktionierten Destillation unterworfen und hierbei schieden sich wiederholt kleine Por-

1) Die von mir benutzten Atomgewichte sind: $H=1,0=16$, $\mathrm{C}=12, \mathrm{~S}=32, \mathrm{Ba}=137,4, \mathrm{Na}=23, \mathrm{Ag}=107,9$. 
tionen Substanz aus, die ebenfalls mit Natriumcarbonatlösung gereinigt wurden und welche alle die Reaktion von Mylius gaben. Außer den oben erwähnten $0,33 \mathrm{~g}$ wurden in dieser Weise $0,07 \mathrm{~g}$ gewonnen, und die Gesamtmenge des Verseifungsproduktes war also $0,40 \mathrm{~g}$.

Das Destillat (zusammen 3 Fraktionen) wurde mit der oben erwähnten Baryumhydratlösung und Phenolphtalein als Indikator titriert. Es wurden zur Neutralisation $2,9 \mathrm{ccm}$ verbraucht. Eine flüchtige Säure ist folglich überdestilliert; daß diese Säure Essigsäure ist, geht aus dem unten zu besprechenden Experimente 4 hervor. $^{1}$ )

Wenn man die in diesem Verseifungsversuche gewonnenen Resultate mit dem obigen Titrierexperimente in alkoholischer Lösung zusammenstellt, so kommt man zu dem bestimmten Resultate, daß die jetzt analysierte Verbindung aus einem Monoacetylderivat der Cholsäure besteht und daß dieses durch Kochen mit Baryumbydratlösung in Baryumcholat und Baryumacetat nach dem folgenden Schema zerfallen ist:

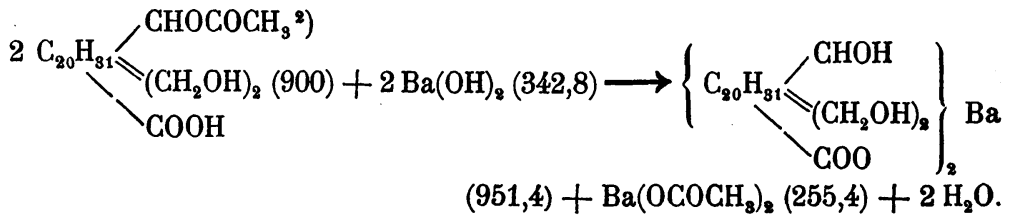

Ein Vergleich der berechneten und gefundenen Werte ergibt nämlich folgendes:

Berechnet: Gefunden :

Schwefelsäure zur Resttitrierung auf die Barytlösung : $10,32 \mathrm{ccm} \quad 9,80 \mathrm{ccm}$

Barytlösung zur Titrierung des Destillates : 3,24 , 2,90 ,

Verseifungsprodukt

: $0,417 \mathrm{~g} \quad 0,40 \mathrm{~g}$

1) Es wurde auch der kleine Rückstand in dem letzten Fraktionierkolben titriert und dabei der Inhalt durch nur einen Tropfen Baryumhydratlösung stark rot gefärbt. Darauf wurde alles mit Sodalösung in der Wärme behandelt; nach dem Filtrieren gab aber Chlorwasserstoffsäure nur eine schwache Opalisierung. Es war also alle flüchtige Säure überdestilliert und auch keine Gallensäure zurückgeblieben.

$\left.{ }^{2}\right)$ Daß die Acetylgruppe in der sekundären Alkoholgruppe stehe, habe ich nicht bewiesen; ich schreibe nur aus gewissen Gründen die Verbindung in dieser Weise. 
Zur Bestimmung der Temperatur, welche in der Lösung beim Kochen mit Essigsäure herrschte, wie auch behufs eines genaueren Studiums der Ausbeuten und des Rohproduktes A habe ich noch zwei Experimente ausgeführt.

Experiment 3. $5 \mathrm{~g}$ Cholsäure und $50 \mathrm{ccm}$ Essigsäure wurden wie in den vorigen Versuchen 8 Stunden 15 Minuten lang erhitzt. Die Temperatur zeigte im Anfang des Experimentes $122^{\circ}$, nach dem Verlaufe einer Stunde $123^{\circ}$ und am Ende des Versuches $125-125,5^{\circ}$.

Mit der Lösung wurde wie oben verfahren. Das entstandene Rohprodukt 1 wurde nach 12 Stunden verarbeitet, es wog $5,8 \mathrm{~g}$ und war durch einen Stich ins Gelbliche gefärbt; das Rohprodukt 2 wog 0,170 g. ${ }^{1}$ ) Die Gewichte der Produkte A und $B$ betrugen 0,97 und $4,32 \mathrm{~g}$ respektive.

In diesem Versuche also aus $5 \mathrm{~g}$ Cholsäure $5,8 \mathrm{~g}$ Rohprodukt 1 und 0,17 g Rohprodukt 2. ${ }^{1}$ ) Die Mengen von A und B waren bezw. 0,97 und 4,32 g.

Experiment 4. $5 \mathrm{~g}$ Cholsäure und $50 \mathrm{ccm}$ Essigsäure wurden während 8 Stunden 30 Minuten erhitzt. Die Temperatur wie im Experiment 3. Das Rohprodukt 1 wog 5,87 g. Die aus der ammoniakalischen Lösung - die Lösung war in diesem Versuche völlig klar, in den übrigen ein wenig opalisierend erzeugte Baryumfällung war etwas gelblich gefärbt, teigig (die teigige Konsistenz verschwand jedoch durch Zusatz von Ammoniak) und blieb im Becherglase 35 Stunden stehen, ehe sie verarbeitet wurde. Im Filtrate von dem Niederschlage entstand binnen kurzem eine neue Fällung, welche in gewöhnlicher Weise behandelt wurde. Die aus diesen beiden Fällungen dargestellten

1) Aus dem Filtrat des Rohproduktes 1 setzten sich nach einiger Zeit Nadeln ab, welche nach dem Auswaschen und Trocknen an der Luft $0,01 \mathrm{~g}$ wogen und nicht die Reaktion von Mylius gaben. Das Filtrat davon wurde jetzt abgedampft, bis die meiste Essigsäure verflüchtigt war, und dann Wasser zugefügt. Die dabei entstandene Fällung wog $0,06 \mathrm{~g}$ und diese zeigte nicht die Reaktion von Mylius. Das Filtrat wurde konzentriert und, wie oben erwähnt, verarbeitet. Durch dreimalige Wiederholung dieser Operation wurden noch $0,10 \mathrm{~g}$, welche nicht die Myliussche Reaktion zeigten, isoliert. Also aus dem essigsauren Filtrat von dem Rohprodukte 2 zusammen $0,17 \mathrm{~g}$. 
Säuren wogen $0,8 \mathrm{~g}$. Im Filtrate von dem zweiten Baryumniederschlage entstand noch eine Fällung, welche nach 19 Stunden wie die übrigen verarbeitet wurde. Die aus derselben erhaltene Säure wog $0,23 \mathrm{~g}$. Die Gesamtmenge von A war also $1,03 \mathrm{~g}$; die Menge von $\mathrm{B} 4,35 \mathrm{~g}$.

Aus $5 \mathrm{~g}$ Cholsäure wurden also in diesem Versuche $5,87 \mathrm{~g}$ Rohprodukt 1 (nebst 0,15 Rohprodukt 2) erhalten. Das Rohprodukt 1 lieferte $1,03 \mathrm{~g}$ von $\mathrm{A}$ und $4,35 \mathrm{~g}$ von $\mathrm{B}$.

Das Produkt A (1,03 g) wurde noch einmal mit Ammoniak und Chlorbaryumlösung behandelt. Aus dem entstandenen Niederschlage (dieser blieb 24 Stunden vor Verarbeitung stehen) wurden mit Salzsäure $0,74 \mathrm{~g}$ Gallensäure, als $A_{1}$ bezeichnet, gewonnen. Das salzsäurehaltige Filtrat von $A_{1}$ ließ ich ins Filtrat von dem Baryumniederschlage hinabfließen; die dabei ausgefällte Säure, welche ich als $A_{2}$ bezeichne, wog $0,21 \mathrm{~g}$.

Aus diesen Zahlen und den entsprechenden im Experimente 3 sehen wir, daß eine ziemlich gute Übereinstimmung zwischen den Ausbeuten herrscht. Weiter dürften wir aus den Gewichten der Rohprodukte vielleicht schließen können, daß außer einem Monoacetylderivat noch eine Verbindung mit höherem Molekulargewicht entstanden ist; wäre nämlich die Cholsäure nur in ein Monoacetylderivat übergegangen, so würde das Gewicht des Rohproduktes nur auf $5,51 \mathrm{~g}$ sich belaufen. Daß der obige Schluß berechtigt ist, zeigt das folgende Experiment.

Untersuchung von $A_{1}$. $0,5620 \mathrm{~g}$ (über Schwefelsäure zum konstanten Gewicht getrocknet) wurden am Rückflußkühler mit $20 \mathrm{ccm}$ von einer Baryumhydratlösung, welche auf $100 \mathrm{ccm}$ 2,78 g Baryumhydrat enthielt, 1 Stunde 42 Minuten lang erhitzt. Im Anfang des Experimentes lag die Substanz wie eine teigige Masse auf dem Boden des Kolbens, der größte Teil der Masse löste sich jedoch allmählich, besonders nachdem Kolben und Kühler ungefähr alle 10 Minuten geschüttelt wurden. Nachdem der Inhalt erkaltet war, wurde mit der im Experiment 2 erwähnten Schwefelsäurelösung mit Phenolphtalein als Indikator titriert und dabei $31,3 \mathrm{ccm}$ bis zur Entfärbung verbraucht. Jetzt wurden zur Ausfällung des Baryums weiter $29,9 \mathrm{ccm}$ von der 
Schwefelsäurelösung zugesetzt und nach einigen Tagen im verschlossenen Kolben der Niederschlag abfiltriert und mit Wasser gewaschen.

Der Niederschlag, wie in Experiment 2, Seite 112, verarbeitet, gab $0,40 \mathrm{~g}$ Gallensäure mit der Reaktion von Mylius.

Das Filtrat von Baryumsulfat und Gallensäure wurde dann in der Hauptsache derselben Behandlung wie im Experiment 2 (S. 112 u. 113) unterworfen und die aus diesem Filtrate isolierte Gallensäure wog $0,08 \mathrm{~g}$; sie gab die Reaktion von Mylius.

Im ganzen wurden also $0,48 \mathrm{~g}$ Verseifungsprodukt erhalten.

Das in die Vorlage übergegangene Destillat wurde mit Natriumhydratlösung titriert (Phenolphtalein als Indikator) und es wurden zur Neutralisation $12,95 \mathrm{ccm}$ derselben verbraucht.

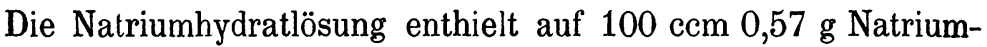
hydrat.

Endlich wurde die neutralisierte, flüchtige Säure mit Silbernitrat versetzt und dabei entstand eine in silberglänzenden Nadeln krystallisierende Verbindung. Mit den Nadeln, aus Wasser umkrystallisiert und über Schwefelsäure bis zur Gewichtskonstanz getrocknet, ist folgende Analyse ausgeführt worden.

Analyse: $0,1027 \mathrm{~g}$ lieferten nach Erhitzung $0,0661 \mathrm{~g}$ Silber oder in Prozenten:

$$
\begin{array}{cc}
\text { Berechnet: } & \text { Gefunden: } \\
\mathrm{Ag}=64,65 & 64,36
\end{array}
$$

Auf Grund dieser Analyse ist also festgestellt, daß die flüchtige Säure Essigsäure ist.

Vergleicht man die oben gefundenen Zahlen mit den für Diacetyl- und Monoacetylderivat berechneten, so ergibt sich folgendes:

Diacetylderivat

Berechnet: Gefunden: Berechnet:

Schwefelsäure zur Barytresttitrierung : $28,58 \mathrm{ccm} \quad 31,30 \mathrm{ccm} \quad 37,24 \mathrm{ccm}$

Natriumhydratlösung zur Titration des

Destillats :

Verseifungsprodukt (Cholsäure):
12,95 >

$0,466 \mathrm{~g}$
Monoacetylderivat

Aus diesen Zahlen könnte man mit Wahrscheinlichkeit schließen, daß ein Gemenge von Mono- und Diacetylderivat und 
zwar in dem Verhältnisse von ungefähr $70 \%$ Diacetyl- und $30 \%$ Monoacetylderivat, welches $31,19 \mathrm{ccm}$ Schwefelsäurelösung, $13,85 \mathrm{ccm}$ Natriumhydratlösung und $0,479 \mathrm{~g}$ Cholsäure erfordert, vorläge. Die nähere Untersuchung des Verseifungsproduktes zeigt indessen, daß die Verhältnisse etwas verwickelter sind.

Untersuchung des Verseifungsproduktes (der Cholsäure). Die obigen $0,48 \mathrm{~g}$ wurden aus $99 \%$ igem Alkohol umkrystallisiert. Nachdem $0,29 \mathrm{~g}^{1}$ ) (6 Fr.) tetraedrische Krystalle isoliert waren, beobachtete ich, daß die Lösung nur schwer weiter krystallisierte. Ich dampfte folglich die letzte Mutterlauge zum Trocknen ab, setzte Ammoniak zu, filtrierte die Lösung und verdünnte dieselbe auf $20 \mathrm{ccm}$. Dann wurde die Lösung mit $10 \mathrm{ccm}$ Chlorbaryumlösung versetzt; dabei entstand ein Niederschlag, welcher sich allmählich als eine teigige Masse abschied. Nach 24 Stunden (die teigige Konsistenz war nun verschwunden) wurde die Fällung abfiltriert und mit einigen Kubikzentimetern von der Chlorbaryumlösung gewaschen. Darauf wurden Niederschlag und das Filtrat mit Chlorwasserstoffsäure behandelt und dabei $0,127 \mathrm{~g}$ und $0,08 \mathrm{~g}$ Säuren respektive erhalten. Aus den 0,08g krystallisierten tetraedrische Krystalle aus.

Pregl $^{2}$ ) und Mylius ${ }^{3}$ ) erwähnen, daß die in Alkalien löslichen Dyslysine durch Zusatz von Chlorbaryumlösung gefällt werden. Aus diesem Grunde kann man vermuten, daß die 0,127 g zum größten Teil aus Dyslysinen ${ }^{4}$ ) bestehen; dieselben müßten durch die Einwirkung von Eisessig auf Cholsäure bei der im Experimente herrschenden Temperatur entstanden sein, im Einklang mit der Dyslysinbildung bei der Einwirkung von konzentrierter Salzsäure auf Cholsäure in der Wärme.

1) $0,2844 \mathrm{~g}$ von diesen wurden abgewogen. Das Gewicht nahm nichts über Schwefelsäure ab. Beim Erhitzen auf $125^{\circ}$ verloren die Krystalle 0,0296 $\mathrm{g}$ an Gewicht oder in 100 Teilen:
Berechnet für $\mathrm{C}_{24} \mathrm{H}_{40} \mathrm{O}_{5}+\mathrm{C}_{2} \mathrm{H}_{6} \mathrm{O}$ :
Gefunden :
$\mathrm{C}_{2} \mathrm{H}_{6} \mathrm{O}=10,1 \%$
$10,4 \%$

2) Sitzungsberichte (l. c.), Bd. CXI, S. 1049.

3) Berichte der Deutsch. chem. Ges., Bd. XX, S. 1978.

4) Ich bezeichne das Produkt im Einklang mit Pregl Dyslysin; ich kann jedoch nichts darüber aussagen, ob ein besonderes Dyslysin oder die sogenannte Choloidinsäure hier vorliegt. 
Fortgesetzte Untersuchungen rücksichtlich der Einwirkung von Eisessig auf Cholsäure sind notwendig, um über diese Frage Klarheit zu bringen; ich glaube aber, daß meine obige Annahme - das Produkt $A_{1}$ besteht aus einem Gemenge von Mono- und Diacetylderivat - in der Hauptsache richtig ist und daß die Dyslysinbildung nur ein sekundärer Prozeß ist.

Untersuchung von dem Produkte B. 0,5653 g von diesem, über Schwefelsäure zur Gewichtskonstanz getrocknet, wurden in $99 \%$ igem Alkohol gelöst und mit Phenolphtalein als Indikator mit einer Natriumhydratlösung, welche auf $1000 \mathrm{ccm}$ $4 ; 08 \mathrm{~g}$ Natriumhydrat enthielt, titriert. Es wurden zur Neutralisation $12,0 \mathrm{ccm}$ derselben verbraucht.

Gefunden: Berechnet:

Auf Monoacetylderivat von der Natronlauge: $12,0 \mathrm{ccm} \quad 12,3 \mathrm{ccm}$

Ich gehe nun zu meinen Experimenten mit Zink, Cholsäure und Eisessig über. Im wesentlichen wurden diese Experimente ebenso wie die Versuche mit Cholsäure und Eisessig ausgeführt; es wurden die verschiedenen Produkte in den Experimenten 1, 2 und zum Teil 3 wie in jener Reihe bezeichnet.

III. Reduktionsversuche mit Zink, Cholsäure und Eisessig.

Experiment 1. $1 \mathrm{~g}$ Cholsäure, in $10 \mathrm{ccm}$ Eisessig gelöst, wurde 4 Stunden 15 Minuten lang mit $4 \mathrm{~g}$ Zinkstaub erhitzt - der Zinkstaub wurde von Zeit zu Zeit hineingeworfen, die letzte Portion nach 1 Stunde 35 Minuten. Nach Hinzufügen von ein wenig Essigsäure wurde der Inhalt filtriert. Um soviel wie möglich von den Reaktionsprodukten zu erhalten, wurden die Zinkreste dreimal mit kalter Essigsäure ${ }^{1}$ ) behandelt, filtriert und dem ersten Filtrate zugefügt. Das Rohprodukt 1, welches erst nach ungefähr 12 Stunden verarbeitet wurde, wog $0,76 \mathrm{~g}$. Als Rohprodukt 2 wurden in drei Fraktionen bezw. $0,08 \mathrm{~g}, 0,11 \mathrm{~g}$ und $0,08 \mathrm{~g}$ oder insgesamt $0,27 \mathrm{~g}$, welche nicht die Reaktion von Mylius gaben, aus dem Filtrate von 1 gewonnen. Das Rohprodukt 1 und die zwei ersten Fraktionen $(0,19 \mathrm{~g})$ des Rohproduktes 2 wurden zusammen verarbeitet. Sie gaben einen

1) Nach viermaligem Behandeln der Zinkreste mit Essigsäure gab das Filtrat nach Wasserzusatz keine Fällung. 
Über die Einwirkung von Reduktionsmitteln auf Cholsäure. 119

Baryumniederschlag, der sich im Anfang wie eine teigige Masse - dieselbe wurde allmählich fest - abschied; darüber setzte sich eine flockige Fällung ab. Nach ungefälır 12 Stunden wurde der Niederschlag verarbeitet und es wogen die Produkte $A$ und B $0,20 \mathrm{~g}$ und $0,57 \mathrm{~g}$ resp.

Experiment 2. $5 \mathrm{~g}$ Cholsäure, $50 \mathrm{ccm}$ Essigsäure und $20 \mathrm{~g}$ Zinkstaub wurden 4 Stunden 15 Minuten lang gekocht und nach dieser Zeit der Inhalt wie im vorigen Experimente verarbeitet. Das Rohprodukt 1 wog 4,74 g. Im Filtrate krystallisierten nach einiger Zeit Nadeln aus, welche $0,08 \mathrm{~g}$ wogen, bei etwa $120^{\circ}$ schmolzen und die Reaktion von Mylius nicht gaben. Das Filtrat von den $0,08 \mathrm{~g}$ lieferte nach Behandeln mit überschüssiger Sodalösung beim Konzentrieren zuerst Zinkcarbonat. Nach Abfiltrieren des Carbonats gab das Filtrat beim Abdampfen Nadeln (2 Frakt.) ${ }^{1}$ ); die Lösung derselben, mit Chlorwasserstoffsäure versetzt, gab auch Nadeln, welche 0,28 g (2 Frakt.) wogen und die Reaktion von Mylius zeigten. Das Rohprodukt 2 macht also eine Mischung von einer Substanz, 0,08 g, welche die Reaktion von Mylius nicht gab, und einer Substanz, 0,28 g, welche diese Reaktion zeigte, aus,

Mit dem Rohprodukt 1 wurde wie im Experiment 1 verfahren - der Baryumniederschlag war in diesem Experimente nicht teigig, ich ließ ihn vor der Verarbeitung während 24 Stunden sich absetzen. Die Gewichte der Produkte A und B betrugen $0,76 \mathrm{~g}$ und $3,7 \mathrm{~g}$ resp.

Untersuchung v on A. Die ganze Menge, 0,76 g, wurde noch einmal der Behandlung mit Chlorbaryumlösung unterworfen - der Baryumniederschlag wurde nach 23 Stunden verarbeitet. Die Gewichte der aus Fällung und Filtrat dargestellten Säuren betrugen $0,58 \mathrm{~g}\left(\mathrm{~A}_{1}\right)$ und $\left.0,02 \mathrm{~g}^{2}\right)\left(\mathrm{A}_{2}\right)$ resp.

Analyse von $A_{1}$. $0,5419 \mathrm{~g}$ (über Schwefelsäure bis zur Gewichtskonstanz getrocknet) wurden am Rückflußkühler während 1 Stunde mit $25 \mathrm{ccm}$ von einer Baryumhydratlösung,

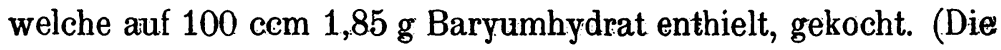

1) Die Mutterlauge von der letzten Fraktion ging verloren.

2) Das Filtrat lieferte nach Behandeln mit Sodalösung in der Wärme und Alkohol $0,11 \mathrm{~g}$ mit der Reaktion von Mylius. 
Substanz löste sich dabei bald klar.) Da die folgende Rücktitrierung mit Schwefelsäure es wahrscheinlich machte, daß nur ein Teil der Substanz von der Baryumhydratlösung gespaltet war, wurde nach der Ausfällung des Baryums als Baryumsulfat alles mit 10\%iger Sodalösung bei Wasserbadtemperatur während 6 Stunden behandelt. Danach wurde (nach dem Filtrieren) Chlorwasserstoffsäure zugesetzt; das nach Auswaschen erhaltene Verseifungsprodukt wog, über Schwefelsäure getrocknet, $0,45 \mathrm{~g}$ und gab die Reaktion von Mylius. Aus dem Filtrat hiervon wurden weiter $0,03 \mathrm{~g}$ (über Schwefelsäure getrocknet) mit der Reaktion von Mylius und also im ganzen 0,48 g Verseifungsprodukt erhalten. Durch Umkrystallisieren aus 99\% igem Alkohol wurden hieraus $0,43 \mathrm{~g}$ tetraedrische Krystalle und aus der letzten Mutterlauge 0,08 g Säure (über Schwefelsäure getrocknet) gewonnen. Die Krystalle $(0,43 \mathrm{~g})$ lieferten bei fraktioniertem Umkrystallisieren zuerst $0,34 \mathrm{~g}$ (3 Frakt.) tetraedrische Krystalle vom Schmelzpunkt $194-195^{\circ}$, dann 0,02 g tetraedrische Krystalle vom Schmelzpunkt $191-193^{\circ}$ und weiter 0,006 g solche Krystalle von einem etwas niedrigeren Schmelzpunkt. Endlich wog die aus der letzten Mutterlauge dargestellte Säure 0,035 g (über Schwefelsäure getrocknet).

Untersuchung von B. 0,3990 g (über Schwefelsäure bis zur Gewichtskonstanz getrocknet) wurden am Rückflußkühler während 40 Minuten mit $10 \mathrm{ccm}$ einer Baryumhydratlösung, welche auf $100 \mathrm{ccm} 2,70 \mathrm{~g}$ Baryumhydrat enthielt, gekocht. Nach dem Erkalten wurde mit der oben gebrauchten Schwefelsäurelösung titriert und dabei zur Resttitrierung auf das Baryumhydrat $12,75 \mathrm{ccm}$ Schwefelsäurelösung verbraucht. Im übrigen wurde wie im Versuche 2, Seite 112 und 113, verfahren.

Das Verseifungsprodukt, welches die Reaktion von Mylius gab, wog $0,34 \mathrm{~g}$.

Zur Titrierung der überdestillierten, flüchtigen Säure wurden mit Phenolphtalein als Indikator 2,45 ccm der Baryumhydratlösung $(2,70 \mathrm{~g}$ Baryumhydrat auf $100 \mathrm{ccm})$ verbraucht.

$\mathrm{Daß}$ diese Säure Essigsäure war, geht aus der folgenden Untersuchung hervor: Aus der soeben gewonnenen Baryumsalzlösung wurde vermittelst Sodalösung eine Natriumsalzlösung dar- 
gestellt, und aus dieser mit Silbernitrat seideglänzende Nadeln erhalten. Diese Nadeln, aus Wasser umkrystallisiert und über Schwefelsäure bis zur Gewichtskonstanz getrocknet, gaben bei der Analyse: $0,0640 \mathrm{~g}$ lieferten nach Glühen $0,0410 \mathrm{~g}$ Silber oder in 100 Teilen:
Berechnet für $\mathrm{AgOCOCH}_{3}$ : $\mathrm{Ag}=64,65 \%$
Gefunden:
$64,06 \%$

Alle diese Versuche haben also gezeigt, daß ein Monoacetylderivat der Cholsäure vorlag:

Berechnet für Monoacetylderivat: Gefunden:

Schwefelsäurelösung zur Resttitrierung

des Baryumhydrats :

$12,85 \mathrm{ccm}$

$12,75 \mathrm{ccm}$

Baryumhydratlösung zur Neutralisation

des Destillats :

Verseifungsprodukt:

$\begin{array}{ll}2,81 & 2,45, \\ 0,36 \mathrm{~g} & 0,34 \mathrm{~g}\end{array}$

Experiment 3. $4,9 \mathrm{~g}$ bei $100^{\circ}$ getrockneter Cholsäure (vor dem Trocknen wurden die Krystalle pulverisiert) wurden mit $50 \mathrm{ccm}$ Essigsäure und $20 \mathrm{~g}$ Zinkstaub während 8 Stunden 15 Minuten erhitzt; im Anfang des Experimentes zeigte das Thermometer $117,5^{\circ}$, am Ende desselben $114^{\circ}$. Nach dem Filtrieren wurden die Zinkreste viermal ${ }^{1}$ ) mit siedender Essigsäure behandelt und diese Filtrate mit dem ersten Filtrate vereinigt. Das Gewicht des Rohproduktes 1 betrug $5,15 \mathrm{~g}$, und vom Rohprodukte 2 wurden $0,41 \mathrm{~g}$ nach Abdampfung (bis so gut wie alle Essigsäure verjagt war) und Verseifung mit Sodalösung erhalten. Dieses Produkt gab die Reaktion von Mylius.

Das Rohprodukt 1 wurde in Ammoniak gelöst, die filtrierte Lösung auf $150 \mathrm{ccm}$ verdünnt und $\mathrm{zu}$ dieser Lösung $30 \mathrm{ccm}$ gesättigte Chlorbaryumlösung gesetzt. Dabei entstand ein Niederschlag (ein Teil des Niederschlages war teigig), der nach 24 Stunden aufs Filter genommen und mit $25 \mathrm{ccm}$ gesättigter Chlorbaryumlösung gewaschen wurde. Im Filtrate entstand dabei eine neue zum Teil teigige Fällung, die nach 20 Stunden abfiltriert und mit $30 \mathrm{ccm}$ gesättigter Chlorbaryumlösung gewaschen wurde. Die Baryumniederschläge, mit Chlorwasserstoffsäure versetzt, gaben $0,23 \mathrm{~g}$ (Frakt. 1) und $0,19 \mathrm{~g}$ (Frakt. 2) Säuren resp. Im

1) Als die Zinkreste noch einmal mit siedender Essigsäure behandelt wurden, entstand im Filtrate durch Wasserzusatz nur eine schwache Opalisierung.

Hoppe-Seyler's Zeitschrift f. physiol. Chemie. L. 
Filtrate von dem letzten Baryumniederschlage schied sich auch eine etwas teigige Fällung ab, die nach 48 Stunden mit $25 \mathrm{ccm}$ gesättigter Chlorbaryumlösung ausgewaschen wurde. Die aus dieser Baryumfällung dargestellte Säure wog 0,08 g (Frakt. 3). Das Gesamtgewicht von A betrug also $0,50 \mathrm{~g}$. Das Produkt B wog 4,41 g. ${ }^{1}$ )

Von dem Produkte A wurden 0,42 $\mathrm{g}$ in Ammoniak gelöst und zum zweiten Male die Lösung $(38 \mathrm{ccm})$ mit Chlorbaryumlösung $(10 \mathrm{ccm})$ gefällt, wobei eine voluminöse Fällung sich abschied. Diese Fällung gab nach dem Waschen mit gesättigter Chlorbaryumlösung $(10 \mathrm{ccm})$ usw. 0,22 g (über Schwefelsäure getrocknet) von dem Produkt $A_{1} \cdot{ }^{2}$ )

Untersuchung von $A_{1}$ und Frakt. 3 (aus A). 0,2972 g, über Schwefelsäure bis zur Gewichtskonstanz getrocknet, wurden am Rückflußkühler mit $12 \mathrm{ccm}$ einer Baryumbydratlösung $(28,6 \mathrm{~g}$ Baryumhydrat auf $1000 \mathrm{ccm}$ ) während 1 Stunde gekocht. So gut wie alle Substanz löste sich bei dem Sieden auf; Kolben und Kühler wurden dann und wann beim Experimente geschüttelt. Darauf wurde wie im Versuch 2, Seite 112 und 113, verfahren.

Von der Schwefelsäurelösung (5,25 g auf $1000 \mathrm{ccm})$ wurden zur Resttitrierung des Baryts 23,1 ccm verbraucht; zur Neutralisation der überdestillierten Essigsäure (mit Phenolphtalein als Indikator) waren $8,25 \mathrm{ccm}$ einer Natriumhydratlösung, die auf $1000 \mathrm{ccm} 4,08 \mathrm{~g}$ Natriumhydrat enthielt, erforderlich und das Verseifungsprodukt, über Schwefelsäure getrocknet, wog $0,24 \mathrm{~g}$. Es zeigte die Reaktion von Mylius.

Die Resultate dieses Experimentes sprechen dafür, daß hier ein Gemenge von etwa 40\% Diacetyl- und 60\% Monoacetylderivat $^{3}$ ) der Cholsäure vorlag:

1) Beim Trocknen über Schwefelsäure verloren $1,8152 \mathrm{~g}$ aus dem lufttrockenen Produkte B $0,0540 \mathrm{~g}$; das macht, auf $4,41 \mathrm{~g}$ berechnet, $0,1312 \mathrm{~g}$ aus.

2) Die Filtrate von den Produkten $B, A_{1}$ und Fraktion 3 lieferten nach Behandlung mit Sodalösung und Alkohol 0,25 g Säure (über Schwefelsäure getrocknet) mit der Reaktion von Mylius.

$\left.{ }^{3}\right)$ Ich will nicht in Abrede stellen, daß das Produkt $A$ aus einer Mischung von Triacetyl- und Monoacetylderivat bestehen kann, finde aber eine solche Annahme nicht wahrscheinlich. 
Berechnet für diese Mischung: Gefunden : Schwefelsäurelösung zur Resttitrierung des Baryts:

$$
23,21 \mathrm{ccm}
$$

$23,1 \mathrm{ccm}$

Natriumhydratlösung zur Neutralisation des Destillats:

Verseifungsprodukt:

$$
\begin{array}{ll}
8,62 & 8,25 \\
0,26 \mathrm{~g} & 0,24 \mathrm{~g}
\end{array}
$$

Das Verseifungsprodukt, aus 99\% igem Alkohol umkrystallisiert, gab 0,175 g (5 Frakt.) tetraedrische Krystalle. Die aus der letzten Mutterlauge ausgefällte Gallensäure wog $0,067 \mathrm{~g}$ (über Schwefelsäure getrocknet), und diese Quantität zeigte keine deutliche Reaktion von Mylius.

Bemerkungen zu den Essigsäureexperimenten.

Aus den Experimenten mit Zink, Cholsäure und Eisessig sieht man also, daß ich keine Reduktion von Cholsäure zu Desoxycholsäure beobachten konnte.

Man sieht auch aus den Essigsäureexperimenten, daß die Substanz, welche aus dem löslichen Baryumsalz isoliert wurde, ein Monoacetylderivat ausmachte und daß das praktisch unlösliche Baryumsalz eine Mischung von Mono- und Diacetylderivaten lieferte. ${ }^{2}$ )

F. Mylius ${ }^{2}$ ) beschreibt auch ein Mono- und ein Diacetylderivat; das erste erhielt er aus Cholsäure mit Essigsäure und Chlorwasserstoffsäure, das letzte aus Cholsäure mit Essigsäureanhydrid. Beide sind nach ihm amorph, lösen sich leicht in organischen Lösungsmitteln, aber nicht in Wasser, und liefern unlösliche Baryumsalze. Seine Analysen des Monoacetylderivats stimmen indessen besser für ein Diacetylderivat.

Obgleich mein Monoacetylderivat so gut wie rein ist, hat dasselbe nur eine unbedeutende Krystallisationsfähigkeit. Das von mir dargestellte Monoacetylderivat ist ebenso wie die Mischung von Mono- und Diacetylderivat nur wenig löslich in Wasser, aber äußerst leicht löslich in Alkohol, Äther, Benzol und Essig-

1) Bei Anwesenheit von Zink entsteht nicht so viel vom Diacetylderivate als sonst; die Temperatur ist ja auch bei den Zinkexperimenten nicht so hoch.

z) Ber. d. Deutsch. chem. Ges., Bd. XIX, 2., S. 2000 (in Ber., Bd. XX, S. 1979 - die Note - behauptet Mylius jedoch, daB das Diacetylderivat eigentlich aus einem Triacetylderivat besteht). 
säure. Dasselbe in krystallisiertem Zustand zu erhalten, hat mir viel Mühe und Zeit gekostet. Nur durch Auflösen einer kleinen Quantität, $0,7 \mathrm{~g}$, in einigen Kubikzentimetern Essigsäure und allmähliche Wasserzusätze (etwas mehr als das Volumen Essigsäure) schieden sich äußerst langsam kleine Nadeln aus. Ich hoffe später durch Elementaranalysen meine soeben beschriebenen Versuche bestätigen zu können.

\section{Schlußanmerkungen.}

Wie aus dem Obigen ersichtlich ist, habe ich also nie Desoxycholsäure, sondern in den alkalischen Reduktionsversuchen unveränderte Cholsäure und in den Versuchen mit Zink und Essigsäure wie in den mit Essigsäure allein nur Acetylderivate erhalten. Wie soll man nun die Experimente und Angaben Vahlens erklären? Die knappen Angaben, die er, namentlich über seine alkalischen Reduktionsversuche, mitgeteilt hat, liefern leider keine genügenden Anhaltspunkte für eine vollständige Erklärung. Ich kann nur die Vermutung aussprechen, daß die von ihm benutzte Cholsäure nicht rein, sondern von seinem sogenannten Reduktionsprodukte, der "Desoxycholsäure», welche vielleicht nichts anderes als Choleinsäure ist, verunreinigt war. Anhaltspunkte für eine solche Annahme finde ich in einer Arbeit von Pregl, 1) welcher gezeigt hat, daß desoxycholsaures $\mathrm{Ba}$ ryum in einer Lösung von Baryumcholat löslich ist. Vahlen hat nämlich zur Reinigung seiner Cholsäure von Choleinsäure (Desoxycholsäure) der Ausfällung der letzten mit Chlorbaryum sich bedient.

Warum aber die Entstehung von Acetylderivaten bei der Einwirkung von Zink und Eisessig auf die Cholsäure Vahlen gänzlich entgangen ist, dafür kann ich keine Erklärung geben.

Upsala, Med. chemisches Laboratorium 1906.

1) Sitzungsberichte, 1. c. S. 1033. Ich werde in einer folgenden Arbeit ein Material quantitativ behandeln, welches außer Cholsäure Choleinsäure enthält. Schon jetzt kann ich erwähnen, daß seine $1 \%$ ige ammoniakalische Lösung nach 24 Stunden keine Fällung für $20 \%$ ige Chlorbaryumlösung gab. Nachdem aber etwa 70\% Cholsäure abgetrennt waren (mit Hilfe von Alkohol), lieferte dagegen der Rückstand für die soeben erwähnte Konzentration einen verhältnismäßig reichlichen Niederschlag. 